\title{
CONSERVATION BEHAVIOR AND THE STRUCTURE OF SATISFACTIONS*
}

\author{
RAYMOND DE YOUNG \\ STEPHEN KAPLAN \\ University of Michigan
}

\begin{abstract}
This article deals with the concerns, the predicted rewards and the satisfactions that people who do conserve derive from their conserving behaviors. In order to investigate the factors that play a role in maintaining energy-conserving behavior, interviews were conducted which focused on the satisfactions that are derived from people's everyday pursuits. The thirty participants were individuals who were known to be concerned about energy conservation issues, and special emphasis was placed on those satisfactions associated with their daily energy conservation activities. Eleven distinct types of satisfactions were found in the data with only one being economic in nature. The range of satisfactions found suggests that many potentially fruitful avenues exist for encouraging the adoption of energy conservation practices among a much broader population.
\end{abstract}

Why do people behave as they do? To the proverbial person on the street this is one of the most obvious questions to be asked of psychology. From a psychological perspective, however, this apparently simple query breaks down into a multitude of often complex issues. Despite considerable attention to many of these issues, there remains an avenue of exploration that is both promising and relatively neglected. For many ordinary, every day behaviors, people do them because they like doing them. They are sources of satisfaction.

* This research was supported, in part, by a grant from the University of Michigan Office of Energy Research (Project No. 65). Deborah Simmons, Janet Talbot, and Rachel Kaplan were also members of the project team.

(C) 1986, Baywood Publishing Co., Inc. 
At the same time there is a more concrete, practical basis for examining the nature of the satisfactions people derive from their everyday activities. One every day activity of considerable interest is conservation. Conservation, despite considerable publicity, remains little practiced by the majority of North Americans. While attitude change [1] and extrinsic incentives [2,3] might seem to be the appropriate means of promoting this important behavior, both have serious enough limitations [4-6] to make alternatives worth exploring.

One might begin by exploring the various explanations people offer for carrying out everyday conservation activities. There are reasons for expecting a rich array of such explanations. Behavior is generally accepted as being multiply determined; one can expect a multitude of motives for a given activity. The term "satisfaction" is used here as a relatively neutral, catch-all term to capture whatever sorts of justifications are offered in discussing conservation behaviors.

This article explores three themes:

1. Are people who conserve somehow different from other people?

2. Does conservation depend on having a special outlook?

3. Is there a single pattern of satisfactions underlying conservation?

\section{MOTIVES FOR CONSERVING}

One possible explanation for conservation behavior is that the people who conserve are a peculiar group of individuals, that they may possess so unique a motivational pattern as to constitute a fringe group relative to the population at large.

It may be the case that the motivation to conserve is derived from a special, perhaps frugal, outlook on life. The tie between an ecological outlook and a conserving lifestyle has been suggested by many writers. The study of environmentally responsible lifestyles has received considerable attention during the last decade, much of it inspired by the work of Gregg on voluntary simplicity $[7,8]$. Leonard-Barton has shown that an individual's tendency toward voluntary simplicity, as characterized by such things as ecological awareness and decreased personal consumption of goods, is a predictor of energy conservation behavior and the intention to purchase solar heating equipment [9] .

The frugality concept has recently been characterized as a central aspect of a conserver society [10]. Yet in discussing a lifestyle of living with less, Johnson has called it, "the subject that often leaves people flat. At best, it seems mundane. At worst, it is downright disagreeable, with no positive attributes other than necessity" [11]. The issue, then, is whether conservation is dependent on an austere outlook or whether it might provide payoffs of a more ordinary, potentially more widely shared kind.

A final theme has to do with the structural nature of one's motivation to conserve. Is it the case that this motive is a unitary, monolithic pattern or is 
there the possibility for mutually supporting patterns? If the motive to conserve in fact involves a choice among alternative patterns then there would be possibilities for many people to contribute to conservation via individually appropriate and satisfying patterns.

There is reason to suspect that some individuals do derive considerable satisfaction from everyday, undramatic conservation activities. It must be emphasized that there may not be many such people, and that their very existence at this point must be considered a hypothesis and not a fact. Nonetheless, as Weigel has suggested, there may be special value in studying the behavior of people who are known to have pro-environmental attitudes [1]. If such people could be found and their satisfactions studied, it might be possible to achieve insight into what would be required to make such activities satisfying to a larger population.

While such a route might seem fraught with risk and uncertainty, there are two factors that speak in its favor. First, it has been repeatedly demonstrated that conservation is by far the most cost effective means of dealing with resource scarcity [12]. Second, satisfaction as a means of fostering conservation may have great advantages over such extrinsic manipulations as incentives. These advantages range from increased cost effectiveness $[13,14]$ to the durability of the behaviors once an intervention has ended $[15,16]$. If one could discover via an understanding of satisfaction how conserving behaviors could be woven into the fabric of everyday life, such activities could become a durable facet of the North American lifestyle.

\section{METHODS}

In order to explore the types of satisfactions that are derived from energy conservation activities as well as other everyday pursuits, an open-ended interview was conducted with thirty participants. Participants were sought among groups with a known interest in the area of conservation. About one-half of the volunteers came from a group formed to work on energy issues in a small city. Other participants were members of an organization with interests in a broad range of conservation issues. Two participants were not members of either group but heard about the study and offered to respond. The interview was described to potential participants as lasting about an hour, and as focusing on everyday activities as well as specific energy-related actions, along with the satisfactions associated with these pursuits.

The sample obviously was not chosen to be representative of the general public. Since we are not yet a conserver society, asking people in general about their conservation activities would yield little of the information being sought. But by recruiting the participants from groups that were actively involved in environmental and energy issues we hoped to provide a rich sample of the diversity of satisfactions that people might derive from energy related activities. 
Questions asked in the interview focused on everyday activities. The interview was structured loosely, and participants were told to consider the questions as only a guide, with expansive answers encouraged. The participants were asked about their transportation and shopping routines, about what kinds of tinkering or puttering around the house they did, and what specific energy-saving habits they practiced. Finally, they were asked to describe any other everyday activities which they particularly enjoyed. In discussing each area, the participants were asked both to name the types of things they did, and to describe the satisfactions or dissatisfactions associated with doing them.

Names and demographic data were not requested as part of the interview. The sample was nearly evenly split between males and females; ages ranged from the twenties to the sixties. A wide variety of income levels was represented; the participants were split approximately evenly between home owners and renters.

Two interviewers were used for this study with each interviewing about one-half of the sample. Extensive notes were taken during each of the interviews and a content analysis of these data was performed. In this analysis eighteen distinct types of satisfactions or justifications were identified as being associated with the participants' everyday and energy-related activities. There was substantial variety in the types of satisfactions discussed, including satisfaction from avoiding wastefulness, savoring comfort and convenience, and social actions.

Once these eighteen distinct types of satisfaction had been established, the interview records were reviewed again and the notes for each participant were scored for both the degrees and the various categories of satisfactions which were expressed. This scoring was done by two individuals working independently and an inter-rater reliability of 94 percent was achieved. A three-level variable was used in scoring each type of satisfaction: high - that type of satisfaction seemed very important to the individual; moderate --that type of satisfaction was discussed, but did not seem especially valued by the individual; or missingthe interview did not include any mention of that specific type of satisfaction.

The resulting eighteen satisfactions variables were reviewed and seven were excluded from further analysis based on their low endorsement. The eleven retained satisfactions had been mentioned (e.g., scored as "high" or "moderate") by at least one-third of the sample. Finally, the correlations among the eleven variables yielded the dominant and secondary themes discussed below. In two instances the intercorrelations among a number of variables suggest the existence of a cluster. These clusters must be considered tentative as a formal cluster or dimensional analy sis was precluded by the small sample size.

\section{RESULTS}

The variety of types of satisfactions which emerged in the interviews is striking (see Table 1). They include economic incentives, a concern for the future and the desire to act in an environmentally prudent way. And they demonstrate the 
Table 1. Satisfaction Themes

\begin{tabular}{|c|c|c|c|c|}
\hline Theme Name & Mean & S.D. & Percent $^{a}$ & $\begin{array}{l}\text { Examples from the } \\
\text { Interview Records }\end{array}$ \\
\hline Conservation Ethic & 2.4 & .72 & 86 & $\begin{array}{l}\text { Waste is thoughtless, stupid, sinful } \\
\text { Save things for the next generation } \\
\text { Repair/reuse rather than replace } \\
\text { Conservation as a duty, responsibility }\end{array}$ \\
\hline Money & 2.4 & .72 & 86 & $\begin{array}{l}\text { The motive of cost avoidance } \\
\text { Money as primary motive to conserve } \\
\text { Heat regulated to save money } \\
\text { Like doing useful and lucrative work }\end{array}$ \\
\hline $\begin{array}{l}\text { Comfort and } \\
\text { Convenience }\end{array}$ & 2.1 & .53 & 90 & $\begin{array}{l}\text { Manage heat for comfort } \\
\text { Freedom not to have to wear sweater } \\
\text { Combine trips and errands to save } \\
\text { time } \\
\text { Live close to work to save time }\end{array}$ \\
\hline $\begin{array}{l}\text { Modern Lifestyle } \\
\text { Independence }\end{array}$ & 1.4 & .55 & 33 & $\begin{array}{l}\text { Freedom from material things } \\
\text { Reduced power of utility companies } \\
\text { Extra food supply for emergencies } \\
\text { Car gives sense of freedom }\end{array}$ \\
\hline $\begin{array}{l}\text { Sensual Quality } \\
\text { of Experiences }\end{array}$ & 1.4 & .70 & 40 & $\begin{array}{l}\text { Quality of daylight } \\
\text { Woodstove aesthetics } \\
\text { Feel of car on long drives } \\
\text { Stimulating feeling of walking }\end{array}$ \\
\hline Image & 1.5 & .56 & 43 & $\begin{array}{l}\text { Clothes as a reflection of self } \\
\text { Garden as an image to others } \\
\text { Looking better } \\
\text { Not want to be too different }\end{array}$ \\
\hline Quality & 1.7 & .60 & 63 & $\begin{array}{l}\text { Durable clothing } \\
\text { Buy quality goods } \\
\text { Hate concept of obsolescence } \\
\text { Fresh, whole, natura! food }\end{array}$ \\
\hline $\begin{array}{l}\text { Social Concern } \\
\text { Helping Others }\end{array}$ & 1.7 & .72 & 60 & $\begin{array}{l}\text { Service on public boards } \\
\text { Aware of effects of own actions } \\
\text { Save people from misinformation } \\
\text { Seeing others' enjoyment }\end{array}$ \\
\hline Social Change & 1.5 & .75 & 40 & $\begin{array}{l}\text { Like to organize } \\
\text { Enjoy stirring things up } \\
\text { Reduce political power of utilities } \\
\text { Bottle bill instills ethics }\end{array}$ \\
\hline $\begin{array}{l}\text { Community } \\
\text { Involvement }\end{array}$ & 1.5 & .54 & 56 & $\begin{array}{l}\text { Keeping up on what is happening } \\
\text { Satisfaction in getting others involved } \\
\text { Social contacts from activities, } \\
\text { walking } \\
\text { Use my own time and effort, not } \\
\text { money }\end{array}$ \\
\hline Challenge & 1.8 & .62 & 70 & $\begin{array}{l}\text { Enjoy learning, problem solving, } \\
\text { challenge } \\
\text { Experiment with food, building solar } \\
\text { house } \\
\text { Challenge of getting by with less } \\
\text { Like competition }\end{array}$ \\
\hline
\end{tabular}

\footnotetext{
${ }^{3}$ The percentage of the participants who scored either high or moderate on this variable.
} 
role of both immediate and long-term considerations in influencing the perceived quality of individual experiences. Actions which serve to enhance the common good are valued, as are activities through which social connections are developed, and pursuits in which the quality of individual experience is enhanced.

\section{The Dominant Satisfaction Themes}

There were three satisfaction themes which were highly endorsed (mean value greater than 2.0) and mentioned by over 85 percent of the participants.

Conservation ethic - This theme reflects a concern for the conservation of resources, a sense that conservation is a duty and that individuals are responsible for the proper use of the earth's resources. As a whole, this theme reflects an ethic and the willingness to act in an environmentally responsible manner even if it is somewhat inconvenient or time consuming.

Money - This theme involves a sense of satisfaction resulting from saving money. Financial considerations, while highly end orsed by many, appear to be sharply distinct, and unrelated to the many other types of satisfaction which result from saving energy as well as from other activities. Even though money was important to the participants, it was not a proxy for other satisfactions and it does not seem to reflect the range of satisfactions which people experience when conserving resources or pursuing their various interests.

Comfort and convenience - This theme includes a desire to live a comfortable existence and a concern for not wasting one's time. The participants reported satisfaction from not having to bundle up with sweaters to stay warm at home, from the efficient use of time, from minimizing the time spent doing errands and from minimizing the amount of time spent commuting by living close to where one works.

\section{Secondary Satisfaction Themes}

There were eight additional satisfaction themes that were moderately endorsed (mean value of at least 1.4 but less than 2.0 ) and mentioned by at least one-third of the participants. Review of the correlation data revealed two clusters of themes. The themes making up the clusters generally had intercorrelations of greater than or equal to .39 with a majority above .46 and also had few and weak correlations with themes outside the clusters. These two clusters have been named Modern Lifestyle and Social Concern (see Table 1).

Modern lifestyle - The Modern Lifestyle cluster consists of four satisfaction themes: Independence, the Sensual Quality of Experiences, Image and Quality, with an average intercorrelation of .43 and an Alpha value of .75. ${ }^{1}$ The

${ }^{1}$ Cronbach's coefficient of internal consistency (Alpha) reflects the degree to which a collection of items "hang together" [17]. Since such items might be thought of as alternate measures of some abstract construct, the Alpha value can be thought of as a rough measure of construct validity [18] 
Independence theme expresses a sense of personal value in maintaining some flexibility in the manner of meeting one's needs and fulfilling one's ongoing responsibilities. This includes freedom from the influences of others and the influence of one's material possessions.

Sensual quality of experiences - This cluster also involves the quality of individual experiences. This includes such things as enjoying long car rides, valuing the aesthetic qualities of woodstoves, and appreciating the quality of daylight as opposed to artificial lighting. In a variety of activities, it was often such more sensual qualities that provided the basis for satisfying experiences, rather than the tangible outcomes of an activity. Also a part of this theme is the satisfaction gained from vigorous exercise. Participants reported satisfaction gained from physical activities; activities that would stimulate one, make one breathe hard. This theme included not only demanding aerobic activities but also just walking about.

Image - The image theme involves a concern for one's appearance, for expressing one's personality through clothing and physical activities (i.e., gardening), and yet not looking too different. And finally, the Quality theme combines an appreciation for quality in clothes, wholeness in food, and durability in goods.

Social concern - The Social Concern cluster is composed of the three satisfaction themes of Helping Others, Social Change and Community Involvement, with an average intercorrelation of .42 and Alpha value of .69 . This cluster reflects satisfactions gained from acting responsibly in the light of larger realities which incorporate social, environmental or ethical issues. Feeling that one is working for the good of others has the potential for being a strong source of satisfaction for individuals.

The central focus of the Helping Others theme is a concern for the common good. It is not explicitly associated with energy issues but addresses matters that are more social in nature. There is an interest in the welfare of the world outside of the self-a concern for the effects one's actions may have upon others. There is also satisfaction gained from sharing information with others, preventing others from being misinformed and seeing others' enjoyment. The Helping Others theme is strongly related to the concept that people may most readily go ahead with those activities that makes sense to themselves and to others.

The Social Change theme reflects satisfaction gained from helping to promote change, stirring things up and reducing the decision making power of utilities. There is also the sense that certain environmental regulations may help to instill an environmental ethic among the public as in the case of bottle bills.

The Community Involvement and Social Contact theme includes satisfactions gained from various types of involvement with the community, enjoying opportunities to be part of what is going on. Participants also enjoyed the informal social contacts which can accompany various activities. There are 
strong parallels between this and the Social Change theme and the satisfaction gained from participation in conservation activities as reported by De Young [19].

Challenge - The Challenge theme, mentioned by 70 percent of the participants, is uncorrelated with the other satisfaction themes. It is intriguing to consider the possibility that experiencing the satisfactions associated with certain challenging activities, that coincidentally conserve resources, may prompt the development of a broader conservation ethic in the typical individual. A person who enjoys problem solving, learning new things or the adventure of getting by with less, may attempt some energy-related projects around the home and in the process gain an appreciation for the values of conservation that may spill over in to other activity.

\section{CONCLUSIONS}

The pattern of results is not only interesting but, in large measure, also encouraging. The findings answer the three questions posed earlier. It seems clear that the people who conserve are not different from other people, they are not members of a spartan elite. Furthermore, conservation does not depend on having a special outlook. Several of the themes (i.e., Modern Lifestyle, Money, Comfort and Convenience) support a mainstream orientation among the participants. While the participants are all active conservers they do not appear to be a fringe group with regard to the population at large. In addition, the themes are not of an overwhelmingly frugal or austere nature. One is struck by the commonplace nature of the satisfaction themes mentioned. This suggests that conservation behavior might be found potentially satisfying to a broader cross-section of the population.

The themes, taken as a whole, indicate that the participants were inclined to interpret their behavior in the larger context. Part of this larger context may involve the ability to justify one's behavior. People seem to seek an interpretation of their behavior that makes sense to them [20] and that they believe would make sense to others [21]. Being able to identify a reasonable justification may be a significant element in the ultimate decision to go ahead with a conservation activity. It is of considerable help, then, that these justifications can come from a variety of sources. With a multi-faceted pattern of satisfactions underlying the practice of conservation there is a choice among alternative motives rather than a single acceptable pattern.

Another striking aspect of the results is that some of these justifications are quite ambivalent with regard to conservation. The themes can be grouped into three categories: 1) those that are highly supportive of resource conservation (i.e., Conservation Ethic), 2) those that are neutral but compatible with conservation (i.e., Money, Social Concern, Challenge), and 3) those that either do or could easily be invoked in favor of non-conserving behavior (i.e., Comfort 
and Convenience, Modern Lifestyle). Fortunately there is more than one way to obtain many of these satisfactions. As an example, consider the Modern Lifestyle cluster. The satisfactions expressed in this cluster might seem to hold the least promise for incorporating resource conservation concerns. In one sense this theme focuses on the affluent lifestyle of Americans, a lifestyle characterized by conspicuous consumption. However, here too there is a potential for encouraging desired behavior patterns by emphasizing qualities such as durability and the sensual qualities of environmentally appropriate products rather than resource conservation as the bases for actions. For example, the desire for quality might be satisfied in an environmentally appropriate manner by purchasing only a few, high-quality and long-lasting items rather than buying large quantities of disposable or less-durable goods.

We set out in this research to explore what linkages, if any, exist between satisfaction and resource conservation activities. The results are encouraging; participants derive a wide variety of satisfactions from ordinary behaviors. And with such a vast array of satisfactions to draw upon, those interested in encouraging conserving behaviors are provided an as yet untapped resource for reaching a much broader audience. Of equal interest, however, is the role played by these satisfactions in increasing the everyday quality of life. By practicing these satisfying activities, the individual not only participates in an environmentally responsible lifestyle but may also lead a more rewarding existence.

\section{REFERENCES}

1. R. H. Weigel, Environmental Attitudes and the Prediction of Behavior, in Environmental Psychology: Directions and Perspectives, N. R. Feimer and E. S. Geller (eds.), Praeger, New York, 1983.

2. J. Cone and S. Hayes, Environmental Problems/Behavioral Solutions, Brooks/Cole, Monterey, California, 1980.

3. E. S. Geller, R. A. Winett, and P. B. Everett, Preserving the Environment: New Strategies for Behavioral Change, Pergamon Press, New York, 1982.

4. M. E. Olsen, Consumers' Attitudes Toward Energy Conservation, Journal of Social Issues, 37, pp. 108-131, 1981.

5. P. C. Stern and G. T. Gardner, Psy chological Research and Energy Policy, American Psychologist, 4, pp. 329-342, 1981.

6. L. McClelland and R. J. Canter, Psychological Research on Energy Conservation: Context, Approaches, Methods, in Advances in Environmental Psychology: Volume 3-Energy Conservation: Psychological Perspectives, A. Baum and J. E. Singer (eds)., Lawrence Erlbaum Associates, Hillsdale, New Jersey, 1981.

7. R. Gregg, Voluntary Simplicity: Part I, Manas, 27, September 4, 1974.

8. R. Gregg, Voluntary Simplicity: Part II, Manas, 27, September 11, 1974.

9. D. Leonard-Barton, Voluntary Simplicity Lifestyles and Energy Conservation, Journal of Consumer Research, 8, pp. 243-252, 1981. 
10. K. E. Henion and T. C. Kinnear (eds.), The Conserver Society, American Marketing Association, Chicago, 1978.

11. W. Johnson, The Future Is Not What It Used to be: Returning to Traditional Values in an Age of Scarcity, Dodd, Mead and Company, New York, 1985.

12. R. Stobaugh and D. Yergin (eds.), Energy Future: Report of the Energy Project at the Harvard Business School, Random House, New York, 1979.

13. H. E. Jacobs and J. S. Bailey, Evaluating Participation in a Residential Recycling Program, Journal of Environmental Systems, 12, pp. 141-152, 1982-1983.

14. H. E. Jacobs, J. S. Bailey, and J. I. Crews, Development and Analysis of a Community-based Resource Recovery Program, Journal of Applied Behavior Analysis, 17, pp. 127-145, 1984.

15. A. U. Pardini and R. D. Katzev, The Effects of Strength of Commitment on Newspaper Recycling, Journal of Environmental Systems, 13, pp. 245-254, 1983-1984.

16. M. R. Lepper and D. Greene (eds.), The Hidden Costs of Rewards: New Perspectives on the Psychology of Human Motivation, Lawrence Erlbaum Associates, Hillsdale, New Jersey, 1978.

17. L. J. Cronbach, Coefficient Alpha and the Internal Structure of Tests, Psychometrika, 16, pp. 297-335, 1951.

18. J. C. Nunnally, Psychometric Theory, McGraw-Hill, New York, 1978.

19. R. DeYoung, Satisfaction from Conservation Activities in North America, Environmental Conservation, 12:3, Autumn 1985 (in press).

20. S. Kaplan and R. Kaplan, Cognition and Environment: Functioning in an Uncertain World, Praeger, New York, 1982.

21. J. L. Sax, Defending the Environment, Vintage Books, New York, 1970.

Direct reprint requests to:

Raymond DeYoung

170 Dana Building

School of Natural Resources

University of Michigan

Ann Arbor, MI 48109-1115 